\title{
THE REGULATION OF IMMUNE SYSTEM BY ANTI-INFLAMMATORY INTERLEUKINS IN HEART DISEASE PATIENTS INFECTED WITH TOXOPLASMOSIS ${ }^{1}$
}

\author{
*Haider S. Abdullhusein, *Basaad A. AL-Aboody, **Ahmad H. Mohammed, \#Redha' Allah M. AL- A' \\ dhami \\ "Department of Biology, College of Science, Thi-Qar University/Iraq \\ ** Department of Pathology analysis, College of Science, Thi-Qar University/ Iraq \\ ***Directorate of Thi-qar Education/Iraq
}

DOI: $10.37648 /$ ijrst.v10i02.003

Received: 15 $5^{\text {th }}$ January, 2020; Accepted: $17^{\text {th }}$ February, 2020; Published: $16^{\text {th }}$ April, 2020

\begin{abstract}
The infection with Toxoplasmosis in humans, especially in people with weak immune system, pregnant women and those with underlying disease could entail serious damage. The objectives of this study are to calculate the prevalence ratio of Toxoplasma Gondi infection in heart disease patients and assess important role of interleukin-10 in immune regulation. About 150 blood samples were collected from heart disease patients in Thi-Qar province and about 100 blood samples were collected from apparently healthy controls. Enzyme linked immunosorbent assay Test (ELISA) was used to test sera of patients and controls to detect anti-Toxoplasma Abs (IgG \& IgM). While the positive samples with toxoplasmosis were tested to detect the levels of IL-10 and IL-12. The overall estimated seroprevalence was $46 \%$ in heart disease patients are higher than those in apparently healthy controls $20 \%$, and there was a significant difference between them. The results of interleukins elucidated high levels of IL-12 82.85 $\mathrm{pg} / \mathrm{ml}$ in heart disease patients infected with toxoplasmosis when compared with control $60.97 \mathrm{pg} / \mathrm{ml}$, and there was significant difference between them. While there was no significant difference in IL-10 in both patients and controls. Also found a significant difference between female and male in patients and controls, in male was higher than those in female. The increased level of IL-12 in patients and controls with toxoplasmosis indicate to the activity of immune system in those patients.

Keywords: Interleukin; Toxoplasmosis; Heart disease; ELISA
\end{abstract}

${ }^{1}$ How to cite the article: Abdullhusein H.S., Al-Aboody B. A., Mohammed A.H., Al-Adhami R.A.M., The Regulation of Immune System by Anti-Inflammatory Interleukins in Heart Disease Patients Infected With Toxoplasmosis, IJRST, Apr-Jun 2020, Vol 10, Issue 2, 16-23, DOI: http://doi.org/10.37648/ijrst.v10i02.003 


\section{INTRODUCTION :}

Toxoplasmosis ranks high on the list of diseases that lead to the death of patients with AIDS. However, following the widespread usage of highly active antiretroviral therapy (HAART) opportunistic infections including $T$. gondiiin AIDS patients have been declining significantly (Dubey, 2010). Protection against $T$. Gondi acquired via oral ingestion of tissue cyst provided by numerous non immunological factors, including barriers that are both chemical and physical (Buzoni-Gatel and Kasper, 2007).Cytokines are protein messengers that convey information between and within the immune system via specific cell surface receptor molecules. Traditionally, Cytokines can be divided into proinflammatory cytokines and anti-inflammatory cytokines, based on global effects in animal models or direct effects on individual immune-cell populations (Stegall , 2010). Interleukins are small protein molecules that signal specific cells to regulate the immune systems of organisms, they are primarily synthetized by $\mathrm{T}$ cells, monocytes, macrophages and endothelial cells (Gomes ,2016). IL-12 is clearly important in initiating a strong and effective cell mediated immunity against $T$. Gondi tachyzoite, IL10 appears to modulate both IL-12 and IFN $-\gamma$ synthesis in vivo, avoiding an excessive immune response that could cause extensive inflammation and host tissue damage. IL-10 and IL- 12 are two major antagonist involved in regulating IFN- $\gamma$ synthesis during the initial phases of infection. (Butcher et. al, 2005).

IL 10 is considered to be an inhibitor of Th1, Th2 and Th17 immune responses (O'Garra , 2007).IL-10 is a protein that also inhibits the synthesis of a number of cytokines, including IFN- $\gamma$, IL-2, IL-3, of IL-12, IL-6 , microglia in the brain, and Granulocytes Macrophage - Stimulating Factor. In structure, IL-10 is a cytokine with anti-inflammatory properties including counteracting the function of Th1 lymphocytes. IL-10 plays a vital role in controlling the inflammatory response during chronic phase of $T$. gondii infection (Wilson et al . 2005). presumed to keep homeostatic network and protect tissue from collateral damage caused by excessive inflammation (Owen et al , 2013).
The recent interest in IL-10 as a potentially protective cytokine in the atherosclerotic process is based on the hypothesis that the development of plaque-forming atherosclerosis is a localized inflammatory process of the vascular wall (Ross ,1999). Indeed, IL-10 may act as an antiatherogenic factor by a number of different mechanisms apart from mere inhibition of proinflammatory cytokines. First, IL-10 interferes with the first step in atherogenesis by inhibiting attachment of circulating immune cells to the endothelium through down-regulation of the adhesion molecules CD18, CD60L, and intercellular adhesion molecule-1 (ICAM-1) (Song et al., 1997). Second, IL-10 inhibits the secretion of chemotactic proteins by macrophages that might attract further leukocytes to the location of subendothelial inflammation(Olszynaet al, 2000 ) Moreover, IL-10 reduces the production of lytic enzymes produced by monocytes, such as matrix-metalloproteinases, and suppresses superoxide anion production, suggesting that IL-10 could prevent plaque destabilization (Lacrazet al. , 1995).

\section{METHODS:}

\subsection{Sample Collection :}

About 150 blood samples had been collected from patients with heart disease, in Thi-qar province. According to gender, the patients divide in to $(81$ male and 69 female) with age ranging 18 and 82 years. Also 100 blood samples had been collected from apparently healthy persons as negative control ,dividing according to gender in to ( 55 males and 45 females) with age ranging 19-56. Six millilitre of blood were collected from each person by using disposable syringes, and then the blood was placed in gel tubes and allowed to clot at room temperature, then centrifuged at 3000 round per minute (rpm) for 10 minutes and sera were dispensed into 4 eppendroftubes, and stored at $-20{ }^{\circ} \mathrm{C}$ until further analysis.

\subsection{Detection of anti- Toxoplasma Gondi antibodies}

The Foresight Toxoplasma IgG and IgM ELISA (Foresight, USA) kit was used to evaluate the titer of 
Abs against Toxoplasmosis. This assay was performed according to manufacturer's procedure.

\subsection{Calculate of serum IL-10 and IL-12 levels by ELISA technique.}

The Elabscience Interleukin (IL-10 and IL-12) ELISA kit was used to evaluate the titer of total Interleukin (IL-10 and IL-12) concentration in human sera by micro plate Enzyme Immunoassay. This assay was performed according to manufacturer's procedure.

\subsection{Statistical analysis}

SPSS version 20 was used to analysis the data in present study with chi-square, $\mathrm{P}$ value $<0.05$ and $\mathrm{T}$ test were considered statistically significant.

\section{RESULTS:}

The sero-prevalence ratio of anti-Toxoplasma $\mathrm{Abs}(\mathrm{IgG}$ and $\operatorname{IgM})$ in both subjects was 69 of 150 (46\%) in heart disease patients, while in controls were 20 of $100(20 \%)$, the current results indicate there is significant differences between them at $\mathrm{p} \leq 0.05$, as summarised in table (1).

Table 1: Seroprevalence of toxoplasmosis in study groups

\begin{tabular}{|c|c|c|c|c|c|}
\hline \multirow{3}{*}{ Number of samples } & \multicolumn{4}{|c|}{ ELISA test } & \multirow{3}{*}{ Total } \\
\hline & \multicolumn{2}{|c|}{ Anti-Toxoplasma positive } & \multicolumn{2}{|c|}{ Anti-Toxoplasma negative } & \\
\hline & Number & $\%$ & Number & $\%$ & \\
\hline Heart disease patients(150) & 69 & 46 & 81 & 54 & 150 \\
\hline Control (100) & 20 & 20 & 80 & 80 & 100 \\
\hline Total & 89 & 35.6 & 161 & 64.4 & 250 \\
\hline Statistical analysis & \multicolumn{5}{|c|}{$\mathrm{X}^{2}=17.691, \mathrm{Df}=1, \mathrm{P} \leq 0.05$} \\
\hline
\end{tabular}

The results show existence of anti-Toxoplasma IgG Abs in both sex, and the higher value in male of heart disease patients was 44 of 81(54.3\%), also the higher value of anti-Toxoplasma IgG Abs in male of controls was 14 of 55 $(25.4 \%)$, whereas the lower value in female in heart disease patients was 250f $69(36.2 \%)$, and the lower value of anti-Toxoplasma IgG Abs in apparently healthy was showed in female 4 of 45 (8.9\%). The results indicate to there is a significant differences at $(\mathrm{p} \leq 0.05)$ between male and female in the seropositivity of anti-Toxoplasma Abs in both subjects, while no significant difference between both gender in the IgM results at $(\mathrm{p} \leq 0.05)$, table $(2)$. 
Table2 : Existence of anti-Toxoplasma Abs in heart disease patients and apparently healthy controls distributed according to gender

\begin{tabular}{|c|c|c|c|c|c|c|c|c|c|c|}
\hline \multirow{3}{*}{$\begin{array}{l}\text { Number } \\
\text { samples }\end{array}$} & \multirow{3}{*}{$\begin{array}{l}\text { gender } \\
\text { group }\end{array}$} & \multicolumn{9}{|c|}{ ELISA test } \\
\hline & & \multicolumn{2}{|c|}{ IgG+ve } & \multicolumn{2}{|c|}{ IgG-ve } & \multicolumn{2}{|c|}{ IgM+ve } & \multicolumn{2}{|c|}{ IgM-ve } & \multirow[t]{2}{*}{ Total } \\
\hline & & $\mathbf{N}$ & $\%$ & $\mathrm{~N}$ & $\%$ & $\mathrm{~N}$ & $\%$ & $\mathbf{N}$ & $\%$ & \\
\hline \multirow{3}{*}{$\begin{array}{l}\text { Heart } \\
\text { disease patients }\end{array}$} & Male & 44 & 54.3 & 37 & 45.7 & 0 & 0 & 81 & 100 & 81 \\
\hline & Female & 25 & 36.2 & 44 & 63.8 & 1 & 1.44 & 68 & 98.55 & \multirow[t]{2}{*}{69} \\
\hline & & \multicolumn{4}{|c|}{$\mathrm{X}^{2}=4.908, \mathrm{Df}=1, \mathrm{P} \leq 0.05$} & \multicolumn{4}{|c|}{$\mathrm{X}^{2}=1.182, \mathrm{Df}=1, \mathrm{P}>0.05$} & \\
\hline \multirow[t]{3}{*}{ Control (100) } & Male & 14 & 25.4 & 41 & 74.6 & 0 & 0 & 55 & 100 & 55 \\
\hline & \multirow[t]{2}{*}{ Female } & 4 & 8.9 & 41 & 91.1 & 2 & 4.6 & 43 & 95.5 & 45 \\
\hline & & \multicolumn{4}{|c|}{$\mathrm{X}^{2}=3.815, \mathrm{Df}=1, \mathrm{P} \leq 0.05$} & \multicolumn{4}{|c|}{$\mathrm{X}^{2}=3.061, \mathrm{Df}=1, \mathrm{P}>0.05$} & 250 \\
\hline
\end{tabular}

In the present study the level of IL-10 and IL-12 were calculated by ELISA in both group (heart disease patients and controls), and showed elevated in the level of IL-12 $(82.85 \mathrm{pg} / \mathrm{ml})$ in heart disease patients compared with controls was $(60.97 \mathrm{pg} / \mathrm{ml})$ and there was significant difference $\mathrm{p}<0.05$ between them. On the other hand no significant difference between heart disease patients and controls in the results of IL-10 was $(7.18 \mathrm{pg} / \mathrm{ml})$ in heart disease patients compared with controls was $(8.14 \mathrm{pg} / \mathrm{ml})$, as show in table (3).

Table 3: The Interleukin levels in heart disease patients with toxoplasmosis and controls

\begin{tabular}{|l|l|l|l|}
\hline Interleukins & Groups & Mean & Std. Deviation \\
\hline \multirow{2}{*}{ IL12 } & Patients(Anti-Toxoplasma positive) & $82.85^{*}$ & 58.95 \\
\cline { 2 - 4 } & Controls(Anti-Toxoplasma negative) & 60.97 & 17.23 \\
\cline { 2 - 4 } & $\mathrm{t}=2.382$, significant P value $=0.020$ & 7.18 & 3.71 \\
\hline \multirow{2}{*}{ *There is a significant difference between groups at $\alpha 0.05$} & 8.14 & 2.30 \\
\hline \multirow{2}{*}{ IL10 } & Patients(Anti-Toxoplasma positive) & \multicolumn{2}{|l}{} \\
\cline { 2 - 4 } & Controls(Anti-Toxoplasma negative) & \multicolumn{2}{|l}{} \\
\cline { 2 - 4 } & $\mathrm{t}=-1.299$, significant P value $=0.199$ & \\
\end{tabular}

Also we calculated the level of interleukins in controls with Toxoplasmosis, and who was not have anti-Toxoplasma, and the results demonstrate there is significant difference at $(\mathrm{p}<0.05)$ in the level of $\mathrm{IL}-12$ between controls with 
toxoplasmosis $(\mathrm{IL}-12=220.24 \mathrm{pg} / \mathrm{ml}$ ), and control Anti-Toxoplasma negative $(\mathrm{IL} 12=60.97 \mathrm{pg} / \mathrm{ml})$. While was no significant difference in IL-10 between both groups, the level of IL-10 in Anti-Toxoplasma positive was (IL-10 = $9.14 \mathrm{pg} / \mathrm{ml})$ and IL-10 in Anti-Toxoplasma negative was (8.14pg/ml), as in table (4).

Table 4:The interleukin levels among control with Toxoplasmosis and who was not have anti-Toxoplasma Ab.

\begin{tabular}{|c|c|c|c|}
\hline \multicolumn{2}{|c|}{ Groups } & \multirow{2}{*}{\begin{tabular}{|l|} 
Mean \\
$220.24 * *$ \\
\end{tabular}} & \multirow{2}{*}{$\begin{array}{l}\text { Std. Deviation } \\
165.96\end{array}$} \\
\hline IL12 & Anti-Toxoplasma positive & & \\
\hline & Anti-Toxoplasma negative & 60.97 & 17.23 \\
\hline & \multicolumn{3}{|c|}{$\mathrm{t}=4.052$, significant $\mathrm{P}$ value $=0.001$} \\
\hline \multicolumn{4}{|c|}{ *There is a significant difference between groups at $\alpha 0.05,0.01$} \\
\hline \multirow[t]{3}{*}{ IL10 } & Anti-Toxoplasma positive & 9.14 & 2.74 \\
\hline & Anti-Toxoplasma negative & 8.14 & 2.30 \\
\hline & \multicolumn{3}{|c|}{$\mathrm{t}=1.207$, significant $\mathrm{P}$ value $=0.236$} \\
\hline The & nt difference between gro & & \\
\hline
\end{tabular}

\section{DISCUSSION:}

In the study indicated that anti-Toxoplasma Abs (IgG) was (46\%) in heart disease patients and (20\%) of apparently healthy controls, the percentage of antitoxoplasmosis Abs (IgG) in overall subjects was $(32.8 \%)$, are higher than those during acute infection (IgM) was (1.2\%), this was higher than results of anti-toxoplasmosis $\mathrm{Ab}(\mathrm{IgG})$ of other studies in the same city by Al-Ghezy, (2012) and Al-Mosawai, (2014) who indicated that the seroprevalence $\operatorname{IgG}$ Toxoplasma Abs was $17.5 \%$ and $11.91 \%$ respectively, while the seroprevalence IgM Toxoplasma in our study was lower than the seroprevalence $\operatorname{IgM}$ in same city by Al-Ghezy, (2012) and Al-Mosawai, (2014) who indicated that the seroprevalence IgM Toxoplasma antibodies was $3.4 \%$ and $5.33 \%$ respectively.

The result of current study was matched with other finding by Tallab et al.,(2012) who recorded that the rate of prevalence anti-Toxoplasma Abs in heart disease patients was $37.9 \%$. The was corresponding with previous studies in other provinces in Iraq by Tawfeeq et al.,(2012) and
Alkhanak et al.,(2015) which recorded that the seroprevalence $\operatorname{IgG}$ Toxoplasma antibodies was $32.4 \%$ and $35.31 \%$ respectively. The results in the present study could be explained by the detail that the group examined consisted of heart disease patients and apparently healthy persons, and IgG positive persons were infected with latent toxoplasmosis without a persistence of $\mathrm{IgM}$ antibodies after acute infection in the past(Carmen et al., 2006).

The presence of anti-Toxoplasma Abs in females was lower than those in males within both subjects, This finding is corresponding with other previous studies by Yassin, (2015) which found higher percentage of seropositivity in males $(71.4 \%)$ than females (28.6\%). In contrast other studies by Kheirabadi et al.,(2013) who found the seroprevalence of anti-Toxoplasma Abs in females higher than males. Whereas other previous studies showed no significant difference between males and females in seroprevalence of toxoplasmosis (Aboelhadid et al., 2013). This may be due to many factors including lower immunity to T.gondii in males as compared to females, social activities and different occupational. Also Females are more 
resistant than males to parasitic infection because of testosterone immunosuppressive properties and gender associated differences in exposure (MoralesMortar et al,.2004). Levels of immunoglobulin's including $\mathrm{IgM}$, IgG in females are higher than those in males with toxoplasmosis (Al-Qureshi,2004).

The results showed elevating in the level of IL-12 in heart disease patients and apparently healthy controls, whom infected with toxoplasmosis comparing with non-infected with toxoplasmosis, this results were matched with results of other studies by Alkhanak et al .,(2015) who found increased in the level of IL-12 in persons with asymptomatic toxoplasmosis in comparison with free-toxoplasmosis persons. Also the results in present study were matched with other previous study by Gomes et al., (2014) who scored increased in the level of IL-12 in persons infected with Toxoplasma in skeletal muscle cells (SkMC), and the present study was different from others $\mathrm{Al}$ Khafajhi et al., (2011) who found reduced in the level of IL-12 in women infected with toxoplasmosis in comparison with free-toxoplasmosis women.

Production of IL-12 and IFN- $\gamma$ is essential to control infection by $T$. gondii, IFN- $\gamma$ synergizes with IL-12 to drive the differentiation of Thp to Th1 phenotype, express IL-12 receptor on $\mathrm{T}$ cells, and inhibit the antagonist IL-4 to prevent the differentiation of Thp towards Th2 phenotype (Cordeiro et al .,2008).The role of IL-12 in toxoplasmosis including induces production of IFN- $\gamma$ from natural killer (NK) cells and $\mathrm{T}$ cells, IFN- $\gamma$ signaling promotes the development of a number of activator of transcription 1 (STAT1)-dependent anti-parasitic effector mechanisms, including reactive oxygen intermediates (ROI) production and p47 GT Paseupregulation (Tait and Hunter, 2009).

On the other hand, the results of IL-10 showed no significant difference between heart disease patients and controls and this may be because the increasing level of IL-12 that have antagonist effect with IL-10. This low level of IL-10 during chronic or past infection with toxoplasmosis in the current study matched the results of other studies (Al-Khafajhi $e t$ al.,2011 and Abdullah et al.,2011) who found reduced in the level of IL-10 in women infected with toxoplasmosis in comparison with free-toxoplasmosis women, IL-10 plays a vital role in controlling the inflammatory response during chronic phase of $T$. gondii infection (Wilson and Wille-Reece,2005). IL10 serves a dual important role during acute toxoplasmosis, by it inhibits IFN- $\gamma$ production and the proliferation of T-lymphocytes, thus preventing a potentially protective Th1 immune response. Such Tcell-dependent immune suppression exerted by IL-10 primarily appears to avoid overwhelming inflammation which eventually leads to death. IL-10 may also deactivate macrophages, thus reducing IFN$\gamma$-induced toxoplasmacidal activity and facilitating intracellular parasite survival. Hence, IL-10-induced immune suppression following infection with $T$. gondii is beneficial for both the parasite and the host and favors a stable host - parasite relationship (EllisNeyer et al.,1997).

\section{REFERENCES:}

* Abdullah,A.D; Mhamood, A.M; Al-Hatemi, B. D. and Mohammed, (2011). The levels of cytokines IL-4, IL10, IL-12p40, IFN- $\gamma$ during acute infection.

* Aboelhadid, S.M; Abdel-Ghany, A.E; Ibrahim, M.A and Mahran, H.A.(2013).Seroprevalence of T. Gondi infection in chickens and humans in BeniSuef, Egypt. Global Vet., 11(2):139-144.

* Al-Ghezy S.J. (2012). Diagnostic study of Toxoplasma gondii and Cytomegalovirus in pregnant and aborted Women with some Epidemiological and Immunity parameter in Thi-Qar Province-Iraq.

* Al-Khafajhi, Y. A. K.; Al-Mammori, R.T. and Al-Awouadi, R. F. (2011). "Assessment of IL-10 and IL-12 Level among Certain Group of Acute Toxoplasmosis Infections in Babylon Aborted Women .” 14(1): 173-80. 
* Alkhanak, Y. R.; Alwachi, S. N.; and Zghair, K. H. (2015). The Effect of Toxoplasmosis Infection on Interleukin-12Level During Human Maturity in Baghdad Province. Department of Biology, College of Science, University of Baghdad. Vol 56.

* AL-Mosawi, R. A. (2014). Diagnostic and epidemiological study of T. Gondi for student of Thi-Qar university by ELISA and Real- Time PCR techniques M.Sc. Thesis. College of Science.

* AL-Qurashi, A. R. (2004).Seroepidemiological study of toxoplasmosis in rural areas in the eastern region of Saudi Arabia. J. Egypt Soc. Parasitol ., 34 (1) :23-34.

* Butcher, BA.; Kim, L.; Panopoulos, AD.; Watowich, SS. Murray, PJ. and Denkers, EY. (2005). IL-10independent STAT3 activation by Toxoplasma Gondi mediates suppression of IL-12and TNF-alpha in host macrophages. Microbiology and Immunology, 174(6):3148-52.

* Buzoni-Gatel, D. and Kasper, L.H. (2007). Innate Immunity in Toxoplasma Gondi Infection 593-608.

* Carmen, S.; Gabriela, B. and Renata, H. (2006).Seroprevalence of Toxoplasma Gondi antibodies in a healthy population from Slovakia.

* Cordeiro, C.A.; Moreira, P.R.; Costa, G.C.; Dutra, W.O.; Campos, W.R and Orefice, F. (2008). Interleukin1 gene polymorphisms and toxoplasmic retinochoroiditis. Mol. Vis.; 14:1845-1849.

* Dubey, J. P. (2010a): Toxoplasmosis of Animals and Humans 2nd edition. CRC Press; Boca Raton, Florida, U.S.A, Pp 1-313.

* Ellis-Neyer, L.; Grüning, G.; Fort, M.; Remington, JS.; Rennick, D. and Hunter, CA. (1997). Role of interleukin-10 in regulation of T-cell-dependent and T-cell-independent mechanisms of resistance to T. gondii. Infect. Immune.; 65: 1675-1682.

* Gazzinelli, RT.; Wysocka, M.; Hieny, S.; Scharton-Kersten, T.; Cheever, A. and Kuhn, R.(1996). In the absence of endogenous IL-10, mice acutely infected with Toxoplasma gondii succumb to a lethal immune response dependent on CD4+ T cells and accompanied by overproduction of IL-12, IFN-gamma and TNF-alpha. J. Immunol.

* Gomes, A. F.; Magalhães, K. G.; Rodrigues, R. M.; de Carvalho, L.; Molinaro, R.; Bozza, P. T. and Barbosa, H. S. (2014). Toxoplasma gondii-skeletal muscle cells interaction increases lipid droplet biogenesis and positively modulates the production of IL-12, IFN-g and PGE2. Parasites \& Vectors, 7, 47.

* Gomes, M. D. S. M.; Vieira, J. L. F.; Cassiano, G. C.; Musset, L.; Legrand, E.; Nacher, M. and Couto, lvaro A. Ri. D.. (2016). Evaluation of circumsporozoite protein of Plasmodium vivax to estimate its prevalence in Oiapoque, Amap., Brazil, bordering French Guiana. Revista Do Instituto de Medicina Tropical de Sao Paulo.

* Kheirabadi, K.P.; Tahmasby, H.; Manouchehri-Naeini, K. and Masoumi-Ghajari, S.(2013). Serological survey of human T. gondii infection in northern and central region of Iran Biological Journal of Microorganism p15-20.

* Lacraz, s.; Nicod, LP. and Chicheportice, R.(1995): IL-10 inhibits metalloproteinase and stimulate TIMP-1 production in human mononuclear phagocytes. J. Clin. Invest.96:2304-2310.

* Morales-Montor, J. A. ; Chararria, M. A.; Deleon, L. L.; Delcastillo, E. G.; Escobedo, E. N.; Sanchez, J. A.; Vargas, M.; Hernandez- Flores, T. and Larralde, R. G. (2004). Host gender in parasitic infection of mammals: an evaluation of the female host supremacy paradigm, Journal of Parasitology. 90:531-546.

* O'Garra, A. Vieira, P.(2007). T(H)1 cells control themselves by producing interleukin-10. Nat. Rev. Immunol.; 7: 425-428.

* Olszyna, DP.; Pajkrt, D.; Lauw, FN. and Van Deventer, SJ.( 2000). Interleukin10 inhibits the release of CC chemokines during human endotoxemia. J. Infect. Dis.; 181:613-620. 
* Owen, JA.; Punt, J.; Stanford, SA. and Jones, PP. (2013).Kuby Immunology.(7thedn)W. H. Freeman and Company, New York.

* Ross R,(1999): Atherosclerosis: An inflammatory disease. NEngl J Med340:115-126.

* Song, S.; Ling-Hu, H. and, KA. (1997): Interleukin-10 inhibits interferon-gamma-induced intercellular adhesion molecule-1gene transcription in human monocytes. Blood 89:4461-4469.

* Stegall, T. (2010) Cytokines, Clinical Immunology \& Serology. (4thedn) F.A. Davis Company, Philadelphia.

* Tait, E. D. and Hunter, C. A. (2009). Advances in understanding immunity to Toxoplasma gondii. Memorias Do InstitutoOswaldo Cruz, 104(2), 201-210.

* Tallab, Tariq. Q.; Al-Autabbi, Jabbar. R. and Al-Umer, Dhiaa. K. (2012). “T. gondii Infection with Ischemic Heart Diseases The Study of Association Between T. gondii Infection with Ischemic Heart Diseases." the Iraqi Postgraduate Medical Journal 11(4): 557-61.

* Tawfeeq, W. F.; Muslim, T. M. and Technologies, M. (2012). Seroprevalence and Associated Factors of Toxoplasma Infection among Sample of Pregnant Women in Wassit Governorate- Iraq, 9(4).

* Yassin, H. M. (2015). Prevalence of toxoplasma gondii in Tuberculosis patients in Sudan, 13(3), 677-680.

* Wilson, EH. and Wille-Reece U. (2005). A critical role for IL-10 in limiting inflammation during toxoplasmic encephalitis. Journal of neuroimmunology. 2005; 165(1-2):63-74. 